\title{
A Survey of Neonatal Resuscitation Facilities in the Urban Setting of Lahore
}

\author{
B K JAVAID T JAVAID I IJAZ Q ZAMAN TI.BHUTTA \\ Department of Pdiatrics, King Edward Medical College, Lahore \\ Correspondence to Dr: Bushra Karim, Assistant Professor Paediatrics. E. mail: bushrakarimjavaid@yahoo.com
}

Objectives: To assess the status of basic facilities and equipment required for neonatal resuscitation and the level of training in neonatal resuscitation of personnel attending neonates at the time of delivery at different health care centers in Lahore. Study design: A cross sectional descriptive epidemiological study. Place and duration: The study was conducted at different health care centers providing obstetrical care in different areas of urban Lahore from February to May 1998. Subjects \& Methods: A survey of about 51 different health care facilities like Private hospitals ,private clinics and $\mathrm{MCH}$ centers in different a reas of Lahore was done. Based on a preset questionnaire the in charge of the relevant place was interviewed regarding availability of requisite equipment and level of training of their staff in neonatal resuscitation. Results: A total of 51 centers in Lahore were surveyed. Out of them 36 were private clinics, 11 private hospitals and 4 MCH Centers. These centers were run by doctors (65\%), LHVs $(23 \%)$ and nurses $(6 \%)$,mid wife, dai, dispenser $(2 \%)$ each. Most of these centers did not have all the required resuscitation equipment, for instance the space for resuscitation was available with $50 \%$, warmers were present $24 \%$, blankets $60 \%$, bulb sucker $49 \%$, electric suction machine $31 \%$, oxygen $51 \%$, bag \&mask $20 \%$ and intubation equipment $16 \%$ were available. The referral transportation was not available in $75 \%$. Regarding training level of the personnel present at the time of delivery $80 \%$ did not have any newborn resuscitation training and only Out of the rest only 8 personnel knew how to intubate the newborn. Conclusion: Most of the centers lack requisite equipment needed for neonatal resuscitation and there is a need for the staff to under go training in neonatal resuscitation.

Key words: asphyxia, neonatal resuscitation, training

Birth asphyxia is still one of the commonest causes of morbidity and mortality in newborns. Over 5.5million babies are born annually in the country. Nearly 270,000 babies die before one month of age ${ }^{10}$. Estimates of the perinatal mortality rate in Pakistan range from 54/1000 births in Karachi to $82 / 1000$ births in Faisalabad". This percentage is 10 times higher than developed countries. Out of these nearly $60 \%$ die during first few days of life 9 The risk factors are, deliveries by unskilled attendants, birth interval $<24$ months, number of pregnancies 6/woman and maternal or paternal illiteracy.

The major causes of neonatal mortality in Pakistan include birth asphyxia $8-28 \%$, low birth or prematurity 14 $26 \%$ tetanus $9-17 \%$ and other infections $21-43 \%$. Birth asphyxias can lead to neurological problems ranging from feeding difficulties to seizures, hearing and visual impairment, paraplegia, quadriplegia, learning disabilities etc.

The aim of conducting the study was to assess the availability of basic facilities and equipment required for neonatal resuscitation and to find out how well trained the obstetrical staff was in neonatal resuscitation.

\section{Methodology}

The study was conducted from February to May 1998. It was a cross sectional descriptive epidemiological study in different health care facilities of urban Lahore to find out about the availability of requisite equipment for neonatal resuscitation and level and knowledge of neonatal resuscitation of the staff involved in handling the new born after delivery. To ensure uniformity, data was collected on a specially designed questionnaire. About 51 randomly selected health care centers that deal with obstetrical care and deliveries were visited by a doctor. $\mathrm{He} /$ she interviewed the health facility owner/ in charge regarding availability of basic neonatal resuscitation facilities, equipment and level of training and staff available in neonatal resuscitation. The information provided was verified.

\section{Results:}

A total of 51 centers were visited in different areas of Lahore. Private hospitals, MCHC and private clinics dealing with obstetrical care were included in the study (Table-1)

Table 1: Health care facilities $(n=51)$

\begin{tabular}{ll}
\hline Centers & $\mathrm{n}=$ \\
\hline Private Clinics & 36 \\
Private hospitals & 11 \\
MCHC & 04 \\
\hline
\end{tabular}

Information about the in charge of obstetrical facility (Table 2).This table shows that not only doctors but LHV, midwives, dai \& dispenser are also running these centers.

Table 2. In charge of facility:

\begin{tabular}{lll}
\hline Personnel & $\mathrm{n}=$ & \%age \\
\hline Doctor & 33 & 65 \\
LHV & 12 & 23 \\
Nurses & 03 & 6 \\
Midwife & 01 & 2 \\
Dai & 01 & 2 \\
Dispenser & 01 & 2 \\
\hline
\end{tabular}


Table -3 shows the basic facilities and equipment available for neonatal resuscitation in various centers. It also shows the discrepancy between reported and actual number of the available facility.

Table-3: Information about equipment available for neonatal resuscitation:

\begin{tabular}{lllll}
\hline $\begin{array}{l}\text { Facility and } \\
\text { equipment }\end{array}$ & $\begin{array}{l}\text { No. centers } \\
\text { reported }\end{array}$ & \%age & $\begin{array}{l}\text { No. of centers } \\
\text { actually present }\end{array}$ & \%age \\
\hline Space & 39 & 76 & 27 & 53 \\
Warmer & 38 & 75 & 12 & 24 \\
Blanket/sheets & 34 & 67 & 30 & 59 \\
Bulb sucker & 36 & 71 & 25 & 49 \\
Electrical suction & 24 & 47 & 16 & 31 \\
Oxygen & 33 & 65 & 26 & 51 \\
Bag and Mask & 22 & 43 & 10 & 20 \\
$\quad \begin{array}{l}\text { Functional } \\
\text { Intubation }\end{array}$ & 15 & 29 & 8 & 16 \\
equipment & & & & \\
\hline
\end{tabular}

The next question asked was whether separate personnel for neonatal resuscitation were available at delivery time or not. Out of 51 centers 44 centers reported to have someone present for neonatal resuscitation while 7 centers did not have such a person available for resuscitation.

The next question asked was, whether available staff got any training in neonatal resuscitation. Table 4 shows out of 51 centers the staff in 34 centers did not receive any training in neonatal resuscitation. Ten centers claimed to have properly trained staff, though only in 8 centers, staff could intubate the baby.

Table-4: Resuscitation training

\begin{tabular}{llc}
\hline $\begin{array}{l}\text { Personnel present for } \\
\text { Resuscitation }\end{array}$ & Resuscitation training & \%age \\
\hline 34 & Untrained & 80 \\
10 & Trained & 20 \\
\hline
\end{tabular}

The last question was regarding availability of transportation for emergency referral. (Table-5)

Table-5. Referral transportation

\begin{tabular}{lll}
\hline No. of Centers & Availability of transportation & $\%$ age \\
\hline 13 & Yes & 25 \\
38 & No & 75 \\
\hline
\end{tabular}

\section{Discussion}

It was observed in this study that in urban Lahore $35 \%$ of obstetrical care is provided by paramedics which includes LHVs, nurses, midwife, dai and dispenser in private sector, rest of the private hospitals and clinics were run by doctors. It shows that maternal health care is being provided by not only doctors but also paramedics. In a survey done by Reproductive Health Services Project in Haripur District In NWFP TBAs provide a majority (63\%) of the delivery care ${ }^{1}$. In another analysis of health Care system it was reported that in 1993 untrained dais conducted the majority of deliveries $(63 \%)$, government health care personnel conducted $20 \%$ and other people conducted $11.5 \%$ of the deliveries. Of these $90.5 \%$ were conducted at home, $5 \%$ at private hospitals, $2 \%$ at government hospitals and $1 \%$ at rural health centers ${ }^{2}$.

Our study shows that basic equipment and facilities required for resuscitation of new born $\mathrm{r}$ ange from $16 \%$ to $71 \%$ Table-2. Simple and inexpensive things like Space for neonatal resuscitation $(53 \%)$, blankets $(59 \%)$, bulb sucker $(49 \%)$, Electrical suction machine $(31 \%)$ and Oxygen $(51 \%)$ were available in almost $50 \%$ of these centers expensive things or the ones that require special training for use like over head warmer (24\%), bag and mask (20\%) and intubation equipment (16\%) were not present in majority of these centers. It is obvious from this study that essential equipment required for neonatal resuscitation is not available in almost half to two thirds of these centers. As sizeable proportion of birth asphyxia is unanticipated so it is important that the staff dealing with obstetrical care should be well trained in neonatal resuscitation and the requisite equipment should be available. A survey carried out in S indh in collaboration with UNICEF revealed that less than half of the secondary care facilities had resuscitation equipment and few had basic neonatal resuscitation drugs ${ }^{3}$. The results of our study are in agreement $w$ ith the a bove mentioned s tudy $\mathrm{c}$ arried out in Sind. Our survey showed that $80 \%$ of the centers had staff that has never received any proper neonatal resuscitation training . Out of the remaining, 10 centers $(20 \%)$ had the staff experienced in resuscitating newborns but only 8 , had the skill to intubate new born if required. The study has highlighted the fact that $65 \%$ centers run by doctors do not have any training in neonatal resuscitation. The situation in this regards is highly unsatisfactory, as basic neonatal resuscitation training to nurses, doctors and paramedics is not given as part of their under graduate training nor is provided later. In a study again from Sind out of 302 doctors and nurses, nearly half of them were not aware of the existence of an ambu bag and only $12 \%$ had access to it ${ }^{4}$. It indicates lack of knowledge and neonatal resuscitation skills even in health care professionals confronted with birth asphyxia every day or on regular basis $^{5}$.

Timely referral of asphyxiated newborns is important. This should be done after initial stabilization to a center which is equipped to handle such babies. In this study only $13(25 \%)$ had readily available transport and $38(75 \%)$ did not have such facility. Based on limited data, Pakistan has the $2^{\text {nd }}$ highest number of neonatal deaths and $4^{\text {th }}$ highest neonatal mortality rate. In one reported discussion about preliminary assessment of priorities in prenatal and neonatal care in Pakistan, it was specifically stated that much work is needed for community based perinatal and newborn care (ref7).In another report from save the children NGO, it was reported that Pakistan still does not have skilled TBAs at community level ${ }^{8}$.

A study was carried out in periurban area in New Delhi India. In this study it was found out that $60 \%$ of deaths occur within 24 hours of recognition of illness, $40 \%$ 
did not seek any outside advise. $70 \%$ of care was sought from private health care providers, half of these providers had no medical education and failed to refer $70 \%$ of newborns who eventually died".

Another study carried out in Maharashtre state, India, promising results were shown. In this study a field trial of home based neonatal care intervention was devised from 1993-1998. These interventions were through trained community health care workers. They were able to reduce perinatal mortality by $71 \%$ and neonatal mortality by $62 \%$ compared to control area ${ }^{10}$.

All of above mentioned studies show that in order to improve neonatal and perinatal mortality rate we have to train our TBAs as well as other personnel involved in neonatal resuscitation at time of delivery and new born care.

Pakistan is s till one of those countries that has very high incidence of neonatal mortality. Birth asphyxia is one of the common and preventable causes of neonatal mortality. Although many NGOs and International Organizations like Save the Children are trying to improve current situation but there is still more to do. This is the time to initiate efforts at local level and join hands with others to improve the current situation.

\section{References:}

1. Kazmi I. B Ari. A. safe motherhood needs assessment. Report. Save the Children, USA. Haripur District Reproductive Health, March 2000
2. WHO, Ministry of Health, Government of Pakistan. Utilization of rural basic Health services in Pakistan, Report of evaluation study. Ministry of Health, Government of Pakistan, WHO (EMR),1993.

3. Rizvi T. Situation analysis of emergency obstetric care in four districts of province Sind. National committee on Maternal Health, Society of Obstetric and Gynaecologists, Ziaudn Medical University, Health department of Sind.Sind:UNICEF, 1999

4. Mahmood N, Rehman S, Leeq A Annual report,20002001.national neonatal G roup. P akistan: P akistan P ediatric Association,2001.

5. Bhutta TI, a survey of newborn resuscitation facilities in Lahore. proceedings of the Symposium on priorities I perinatal and neonatal care in south asia.199.8 september;aga khan University,Karachi,Pakistan.

6. Cost effective community based intervention in perinatal newborn care http//wwwglobalforumhealth.org/ forum7/ cdromforum 7/Monday/1dec 2003.

7. Pakistan: newborns face uphill battle to earn life (Islamabad, 25 Feb. 2004(IRIN).

8. Research plan and progress.

9. Hans Tredsson, Jose Martines, Jelka Zupin. Journal of perinatology (2002) 22, s12-s19 doi:10.1038/sj.jp.7210809.

10. [Gsd-list]270,000 newborns die every yr in Pakistan: report SDNP Info May 2002 15:48:43.

11. Results from Recent research. Home based neonatal care in Gadchiroli India.Abhay T Bang. Journal of

12. Perinatology (2002)22, s20-s24 doi:10.1038/sj.jp

13. Fikree FF, Gray RH. Demographic survey of the level and determinants of perinatal mortality in Karachi, Pakistan. Pediatr Perinatal Epidem 1996;10:86-96. 